\title{
Anabases
}

ANABASES Traditions et réceptions de l'Antiquité

22 | 2015

Varia

\section{Anne-Emmanuelle VEÏSSE, Stéphanie WACKENIER (éd.), L'armée en Égypte aux époques perse, ptolémaïque} et romaine

Dan Dana

\section{OpenEdition}

\section{Journals}

Édition électronique

URL : http://journals.openedition.org/anabases/5525

DOI : 10.4000/anabases.5525

ISSN : 2256-9421

Éditeur

E.R.A.S.M.E.

\section{Édition imprimée}

Date de publication : 20 octobre 2015

Pagination : 287-286

ISSN : 1774-4296

\section{Référence électronique}

Dan Dana, «Anne-Emmanuelle veïsse, Stéphanie wACKENIER (éd.), L'armée en Égypte aux époques perse, ptolémaïque et romaine », Anabases [En ligne], 22 | 2015, mis en ligne le 20 octobre 2015, consulté le 22 septembre 2020. URL : http://journals.openedition.org/anabases/5525 ; DOI : https://doi.org/ 10.4000/anabases.5525

Ce document a été généré automatiquement le 22 septembre 2020

(c) Anabases 


\title{
Anne-Emmanuelle vEÏsse, Stéphanie WACKENIER (éd.), L'armée en Égypte aux époques perse, ptolémaïque et romaine
}

\author{
Dan Dana
}

\section{RÉFÉRENCE}

Anne-Emmanuelle VEÏSSE, Stéphanie WACKENIER (éd.), L'armée en Égypte aux époques perse, ptolémaïque et romaine, Genève, Droz (Hautes Études du Monde Gréco-Romain 51 ; Cahiers de l'Atelier Aigyptos 2), 2014, 255 p.

42,20 euros / ISBN 978-2-600-01377-2.

1 Ce recueil réunit les sept communications d'une table-ronde de l'association Aigyptos (Paris, juin 2009). La brève introduction des éditrices justifie le choix du thème : la composition de l'armée d'Égypte aux époques où le pays est dirigé par des pouvoirs non-égyptiens, avec une attention particulière aux modalités de contrôle du territoire et aux rapports entre armée et société. Les articles exploitent les données littéraires, épigraphiques et archéologiques, et notamment la riche documentation papyrologique, plurilingue.

2 A. Pétigny étudie les garnisons cosmopolites établies aux frontières de l'Égypte aux v $\mathrm{v}^{\mathrm{e}}$ $\mathrm{IV}^{\mathrm{e}}$ siècles av. J.-C. et souligne la continuité en matière de recours aux étrangers entre la domination perse (525-404, 343-332) et les dynastes indigènes, qui ont fait appel aussi bien aux mercenaires, aux conscrits impériaux allogènes, qu'aux nomades des territoires frontaliers.

Deux articles traitent du Delta, région mal connue en l'absence de papyrus, en contraste avec le Fayoum et la Haute Égypte. B. Redon reconstitue le maillage militaire relativement dense du Delta égyptien sous les Lagides, à l'aide de mentions littéraires, d'inscriptions émanant de soldats, ainsi que de données archéologiques plus récentes. Elle remarque la progression du maillage militaire, grâce à des soldats récemment 
installés en Égypte, parfois organisés dans des politeumata. Le Delta, région stratégique qui assurait la sécurité extérieure du royaume, fut doublement surveillé en raison de sa population agitée. La politique volontaire et dynamique du pouvoir central permit le retour du Delta à la stabilité au milieu du II $^{\mathrm{e}}$ siècle, à l'instar de la Thébaïde. Au terme d'une analyse détaillée, J.-Y. Carrez-Maratray propose une nouvelle lecture de la statue du syngénès Aristonikos, qui se trouve au musée du Caire ; il l'identifie à l'« Aristonikos de Polybe ", ministre de Ptolémée V, connu pour son rôle essentiel dans la répression des révoltes en Haute-Égypte et dans le Delta central, d'où provient la statue. Cet exemple conjugue « l'enracinement gréco-macédonien au cœur du territoire égyptien » et la piété envers l'Amon de To-bener, dans cet espace de " légitimation hellénique " qu'était devenu le Delta. A contrario, G. Gorre revisite l'identification comme stratège du Tentyrite de Korax, fils de Ptolémée-Psenpchois (inscriptions hiéroglyphiques du $\mathrm{I}^{\mathrm{er}}$ siècle av. J.-C.), qui fut à la fois membre notable du clergé de Dendérah et officier de la Couronne ; rejetant son appartenance à une famille de stratèges de la Tentyrite, il fait de lui un laarque, un officier ptolémaïque commandant de troupes égyptiennes.

Grâce aux archives grecques et démotiques, K. Vandorpe reconstitue l'organisation militaire de la Haute Égypte aux $\mathrm{II}^{\mathrm{e}} \mathrm{I}^{\mathrm{er}}$ siècle av. J.-C. Alors que les clérouques sont minoritaires, les misthophoroi, soldats recevant une solde, sont essentiellement d'origine égyptienne, mais dotés d'ethniques étrangers (" Macédonien », " Perse »), moyen de s'assurer leur loyauté. Des réformes administratives et militaires sont engagées après les révoltes ; les troupes régulières sont sous-représentées, alors que le recrutement local s'intensifie, combinant hellénisation et promotion sociale, mais aussi loyauté envers le roi. De cette manière, les talents d'organisateurs de Ptolémée VI et de Ptolémée VIII sont reconnus, loin de la tenace opinion commune d'une période de crise et de déclin.

5 Le même questionnement des partis-pris historiographiques nourrit l'étude stimulante de Chr. Fischer-Bovet. Ainsi, les demandes d'inviolabilité (asylia) formulées par les officiers lagides du Fayoum en faveur des temples égyptiens dans la seconde moitié du $\mathrm{II}^{\mathrm{e}}$ et au $\mathrm{I}^{\mathrm{er}}$ siècle av. J.-C., loin d'être le signe d'un affaiblissement du pouvoir central visà-vis du clergé et l'administration locale, illustrent, en plus des traces de tensions locales dans les pétitions, l'intérêt des soldats envers les temples. Ce phénomène s'explique par "les liens sociaux qui se sont progressivement tissés " entre les militaires grecs ou gréco-égyptiens et l'élite locale du clergé égyptien, dans le contexte des profondes restructurations qui eurent lieu entre 220 et 160 av. J.-C. Chr. FischerBovet établit un lien causal entre le rôle unificateur de l'armée au niveau local et les demandes d'asylie par les militaires, et note les liens tissés entre les membres de la garde royale et les habitants de la chôra. L'auteur dépasse ainsi la dichotomie entre le déclin du pouvoir royal vis-à-vis du clergé (Ch. Préaux, Fr. Dunand) et la dépendance des temples à l'égard des institutions grecques (M. Rostovtzeff, J. Bingen). Elle insiste, en revanche, sur le lien étroit entre militaires et élites locales égyptiennes, à une époque où l'armée, force unificatrice entre les divers groupes ethniques, favorise l'essor d'une culture gréco-égyptienne. Il convient désormais d'aller au-delà du cadre d'un supposé conflit entre roi et clergé, puisqu'au niveau local temples et rois forment une entité. Promotion des dieux ou des villages auxquels les soldats sont attachés, d'une part, expression de la loyauté au roi des membres de l'armée, de l'autre, mais aussi attachement réel aux dieux locaux, sont tout autant de facettes du phénomène analysé. 
6 Dans sa riche analyse épigraphique et iconographique des épitaphes latines des légionnaires en garnison à Alexandrie, avec des corrections et des nouveautés, Fr. Kayser révèle la manière dont les soldats romains d'Égypte se sont insérés dans leur nouveau milieu socio-culturel. Il constate une nette évolution, aussi bien du formulaire que de l'iconographie, entre les usages du i ${ }^{\text {er }}$ (légions XXII Deiotariana et III Cyrenaica) au III $^{\mathrm{e}}$ siècle (légion II Traiana) : on assiste à l'importation de modèles romains, qui sont déterminants, mais qui portent à la fois l'empreinte du contexte régional, de l'Orient romain hellénophone et parfois même d'un troisième niveau, égyptien. Ces épitaphes, qu'il qualifie davantage d'éléments de romanité que de romanisation, nous renseignent sur un véritable " îlot de romanité dans un océan d'hellénisme ", tout en étant des documents alexandrins.

7 Des illustrations de qualité (photos, cartes, schémas) et des index de sources, de noms et géographique complètent ce recueil. Il combine des études de cas sensibles aux contextes et des synthèses qui renouvellent la question du contrôle militaire de l'Égypte, par le croisement des sources, le réexamen de la vulgate historiographique et une analyse attentive aux rapports sociaux.

\section{AUTEURS}

\section{DAN DANA}

CNRS / ANHIMA

ddana_ddan@yahoo.com 